\title{
La persistencia de la segregación y la desigualdad en barrios socialmente diversos: un estudio de caso en La Florida, Santiago
}

Javier Ruiz-Tagle. Universidad de Chile, Santiago, Chile.

RESUMEN | Se ha discutido crecientemente acerca de barrios socialmente mixtos, en función de revertir los problemas sociales adicionales que la concentración de la pobreza supuestamente produce. Dichos estudios destacan los aspectos positivos de la cercanía entre condominios cerrados y viviendas sociales, pero se han sobreestimado los cambios simbólicos por sobre problemas más críticos de persistente segregación y desigualdad. Basado en una perspectiva multidimensional de la integración socioespacial, se presenta un estudio de caso en La Florida, Santiago: un barrio con una historia de tomas de terreno, proyectos de vivienda social y, recientemente, nueva población de clase media y media-alta. El caso muestra lo compleja que ha sido esta coexistencia, y cómo la segregación se ha ido moviendo desde la vivienda hacia otras esferas de socialización. Se recalca la necesidad de una visión institucional y crítica acerca de la mixtura social, los efectos de barrio y la redistribución territorial de recursos.

PALABRAS CLAVE | integración social, segregación, sociología urbana.

ABSTRACT | Increasing discussions about socially mixed neighborhoods have been developing in order to reverse additional social problems allegedly produced by concentrated poverty. Those studies highlight the positive aspects of the proximity between gated communities and social housing, but they overestimate symbolic changes over more critical problems of persistent segregation and inequality. Based on a multi-dimensional perspective of socio-spatial integration, a case study in La Florida (Santiago, Chile) is presented: a neighborhood with a history of land squatters, social housing projects, and recently, new middle and upper-middle class population. The case shows how complex this coexistence has been, and how segregation has been moving from housing to other spheres of socialization. The need for an institutional and critical vision on social mix, neighborhood effects and territorial resource redistribution is stressed.

KEYWORDS | social integration, segregation, urban sociology.

Recibido el 10 de enero de 2014, aprobado el 23 de agosto de 2014

E-mail: javier.ruiztagle@gmail.com, jruiztagle@uchile.cl 


\section{Introducción}

La ciudad de Santiago ha crecido con grandes áreas segregadas de población pobre, y las transformaciones neoliberales hicieron la situación aún peor: bajos estándares de urbanización y equipamiento; educación y salud segregadas y de mala calidad; municipios con déficit financieros; y enormes diferencias de ingreso con las clases altas (Barozet, 2011; Rodríguez \& Winchester, 2001). Sin embargo, las estrategias inmobiliarias de condominios cerrados en algunos sectores han puesto en un mismo lugar a habitantes de clase media, con otros de clase baja establecidos en proyectos de vivienda social. En estos casos, la llegada de familias de más alto estatus ha modificado la calidad de los servicios públicos y privados, incentivando debates acerca de la posibilidad de tener barrios menos segregados, y creando altas expectativas sobre la mezcla social (Sabatini \& Salcedo, 2007). No obstante, no está claro del todo que estos beneficios sean instrumentales o meramente simbólicos, debido a las persistentes divisiones en otras esferas de socialización. Mediante un estudio de caso, este artículo investiga cómo esta proximidad física afecta la integración de grupos excluidos en varias dimensiones: acceso a oportunidades, relaciones entre grupos y construcciones simbólicas de comunidad.

En las secciones siguientes, luego del marco teórico y de la presentación del caso, se describen primero las oportunidades para la clase baja en términos de trabajo y educación. Segundo, se muestran las relaciones entre grupos y la importancia del clasismo. Tercero, se describen los problemas de seguridad y uso del espacio público. Se concluye con reflexiones acerca de la integración socioespacial, la literatura sobre barrios diversos, y algunas implicancias para las políticas urbanas.

\section{Marco teórico}

El concepto de segregación residencial es generalmente usado para referirse a la concentración espacial de grupos sociales debido a fuerzas de exclusión de raza y/o clase (Marcuse, 2005). En las últimas décadas, la literatura internacional dominante se ha enfocado en la concentración de la pobreza y sus consecuencias: los llamados "efectos de barrio" (Jargowsky, 1997; Massey \& Denton, 1993; Sampson, Morenoff \& Gannon-Rowley, 2002; Wilson, 1987). Sin embargo, autores más críticos afirman que las consecuencias de la segregación se relacionan con estrategias de subsistencia en contextos de un alejamiento general del Estado y que los efectos de barrio son en realidad el resultado de funcionamientos institucionales específicos (Gans, 2008; Wacquant, 2009). En el campo de lo simbólico, se dice que el espacio habitado constituye un símbolo del espacio social (Bourdieu, 1999) y que la segregación corresponde a la construcción imaginaria del "otro" y de su hábitat (Saravi, 2008).

El estudio de la integración social, por su parte, ha pasado por tres tradiciones diferentes. Primero, la sociología funcionalista concibe la integración como una descripción neutral de relaciones sociales, ligada al consenso, al equilibrio social y al orden (Durkheim, 1997). Segundo, la sociología progresista, pos-Segunda Guerra Mundial, vincula la integración con las ideas positivas de inclusión, derechos y ciudadanía, más allá de la mera carencia de recursos (Strobl, 2007). Y tercero, la 
integración ha sido estudiada en Estados Unidos desde el punto de vista de una reacción negativa a las políticas de desegregación y mezcla social, sobre todo en barrios y escuelas, lo que es capturado en la idea de "agotamiento de integración" (Cashin, 2004). Las políticas de mixtura social a nivel de barrios han emergido en distintos momentos de la historia (Arthurson, 2012): en la Gran Bretańa del siglo XIX, basadas en visiones utópicas de reunificación; después de la Segunda Guerra Mundial, sustentadas en ideales de igualdad; y recientemente, orientadas a abordar los problemas sociales de la concentración de la pobreza (política que se está expandiendo en varios contextos neoliberales). Aquí se sostiene que cuatro ideas han servido de soporte para las políticas recientes de mezcla social: i) la representación de los guetos como formas sociales patológicas (Jargowsky, 1997; Massey \& Denton, 1993; Wilson, 1987); ii) el vínculo entre concentración de la pobreza y problemas sociales, o "efectos de barrio" (Sampson et al., 2002); iii) la sugerencia implícita de que geografías de oportunidad siguen a los grupos de más alto estatus y luego "chorrean" al resto (Galster \& Killen, 1995), y iv) los supuestos de que los barrios socialmente mixtos crearían un círculo virtuoso de redes sociales, control social y comportamientos ejemplares (DeFilippis \& Fraser, 2010).

En Chile, aun en pleno proceso de discusión e incipiente implementación de políticas de mezcla social, los principales casos de diversidad socioeconómica se han observado en áreas periféricas pobres que han sido invadidas por condominios cerrados (Sabatini, Cáceres \& Cerda, 2001). Estos casos han sido explicados en términos de una dispersión de las elites a través de la adquisición de suelo barato y la construcción de barrios lo suficientemente cerrados como para generar un atractivo inmobiliario (Salcedo \& Torres, 2004). Junto con explicar el proceso de aparición, dichos estudios se han enfocado principalmente en destacar los beneficios de este tipo de barrios; ciertos intercambios funcionales (sobre todo servicio doméstico), menor estigmatización, atracción de servicios privados, y un entorno urbano reformado (Sabatini \& Salcedo, 2007; Salcedo \& Torres, 2004). Sin embargo, estas investigaciones tienden a subvalorar varios problemas críticos (Ducci, 2000; Hidalgo, 2004; F. Pérez, 2006; Ruiz-Tagle \& López, 2014), vinculados con las relaciones sociales más allá del intercambio de bienes y servicios, la violencia simbólica de los muros y las rejas, las posibilidades efectivas de movilidad social, y el rol de algunas organizaciones sociales (revirtiendo o agudizando la segregación). En Chile, la noción de espacio público y los valores de integración social se han debilitado (Márquez \& Pérez, 2008), y en ese sentido, como seńala Bourdieu (1999), la proximidad entre grupos sociales no tendría un efecto en la cohesión social. Es más, agrega el mismo autor, la creación de relaciones sociales entre grupos muy dispares se hace muy improbable cuando hay diferentes tipos de capital económico, político, cultural y simbólico. Pese a esto, los estudios sobre condominios cerrados en áreas pobres han logrado consolidar, en ciertos círculos de discusión de políticas públicas urbanas en Chile, lo que se ha llamado el "consenso de la dispersión" (Arthurson, 2012).

En resumen, la integración social es vista como un ideal en contextos de segregación histórica, pero es a menudo reducida a una mera mezcla de diferentes grupos en el espacio, sin tomarse en cuenta varios otros aspectos que contribuyen y mantienen la exclusión. Desde una visión más exhaustiva, se concibe aquí la integración 
socioespacial como una relación compuesta por cuatro dimensiones (Ruiz-Tagle, 2013): i) fisica, proximidad entre grupos diferentes; ii) funcional, acceso efectivo a oportunidades y servicios; iii) relacional, interacciones no-jerárquicas, y iv) simbólica, identificación con un territorio común.

\section{Área de La Loma en La Florida: caso y métodos}

Se eligió un caso de estudio en la comuna de La Florida (Santiago), por ser esta de alguna manera "un espejo de Chile" (De la Jara, 2003), en términos de sus recientes transformaciones sociales, culturales, económicas y urbanas. La comuna creció fragmentada entre un sector surponiente que recibió la gran mayoría de las viviendas sociales, y un sector oriente, anteriormente semirrural, que recibió las villas de sectores medios. Su configuración actual, entonces, es de fuertes contradicciones entre los grandes proyectos inmobiliarios (comerciales, habitacionales, educacionales, de salud, etcétera), y la pobreza y los déficit de equipamiento urbano. Como intersección de estos dos mundos, se eligió el área alrededor de La Loma. La figura 1 muestra, a la izquierda, los límites del área escogida y la localización de viviendas sociales y condominios cerrados; y a la derecha, la distribución socioeconómica de la población.

FIGURA I | Viviendas sociales y condominios cerrados (izquierda), y distribución socioeconómica (derecha)

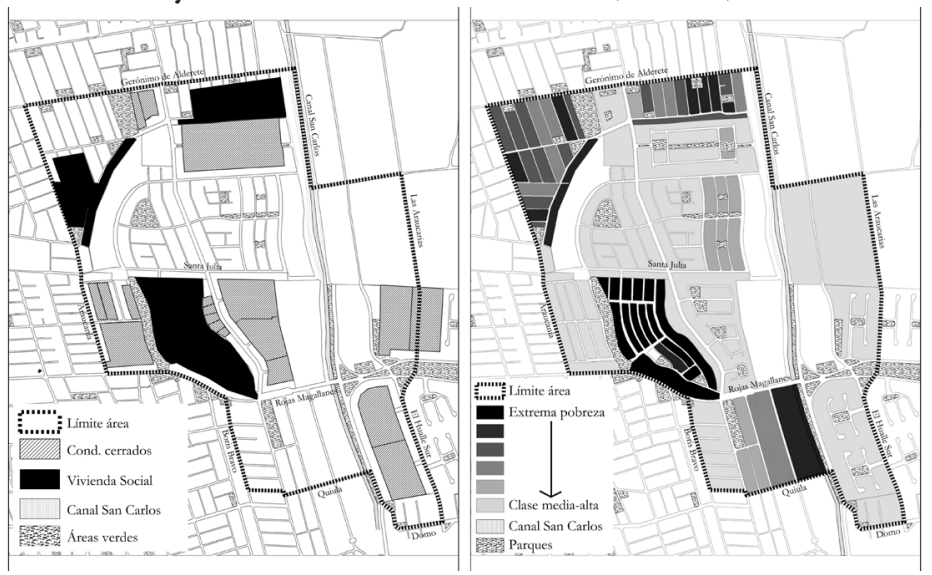

FUENTE IZQUIERDA, ELABORACIÓN PROPIA. DERECHA, ESTIMACIÓN (VÉASE ANEXO, SECCIÓN I)

El área alrededor de La Loma empezó a ser poblada hace más de medio siglo. Los asentamientos semirrurales de Lo Cañas y de Santa Sofía se establecieron entre los ańos cuarenta y cincuenta, y en 1970, los trabajadores agrícolas del sector decidieron tomarse el terreno de La Loma, que hasta el momento permanecía desocupado. Allí construyeron sus propias viviendas y recién en 1995 lograron urbanizarlo y obtener títulos de dominio. En los años ochenta y noventa, la expansión de la ciudad llegó hasta los alrededores de La Loma, con villas de vivienda social (Raúl Silva Henríquez 
y Carlos Witting) y villas de clase media y media-baja (Jardín Alto y Jardín del Edén). Pero desde 2000 se fue dando una transformación mayor. Comenzaron a construirse condominios cerrados y barrios completamente nuevos para familias de la clase media-alta (Llanos de Lo Cañas, Villa Parque Las Mercedes y Jardines de la Viña), lo cual ha cambiado drásticamente la calidad de los servicios públicos y privados en el sector y, sobre todo, las relaciones con los vecinos y con el Municipio de La Florida. En la actualidad, con una población de casi 10.000 personas, esta área presenta una gran diversidad socioeconómica: un 33\% corresponde al decil más rico de Chile, y un $18 \%$ a los cuatro deciles más pobres. La figura 2 y el cuadro 1 muestran fotografías y una síntesis del cambio sociodemográfico, respectivamente.

FIGURA 2 Fotos de distintos conjuntos de vivienda y servicios en el sector

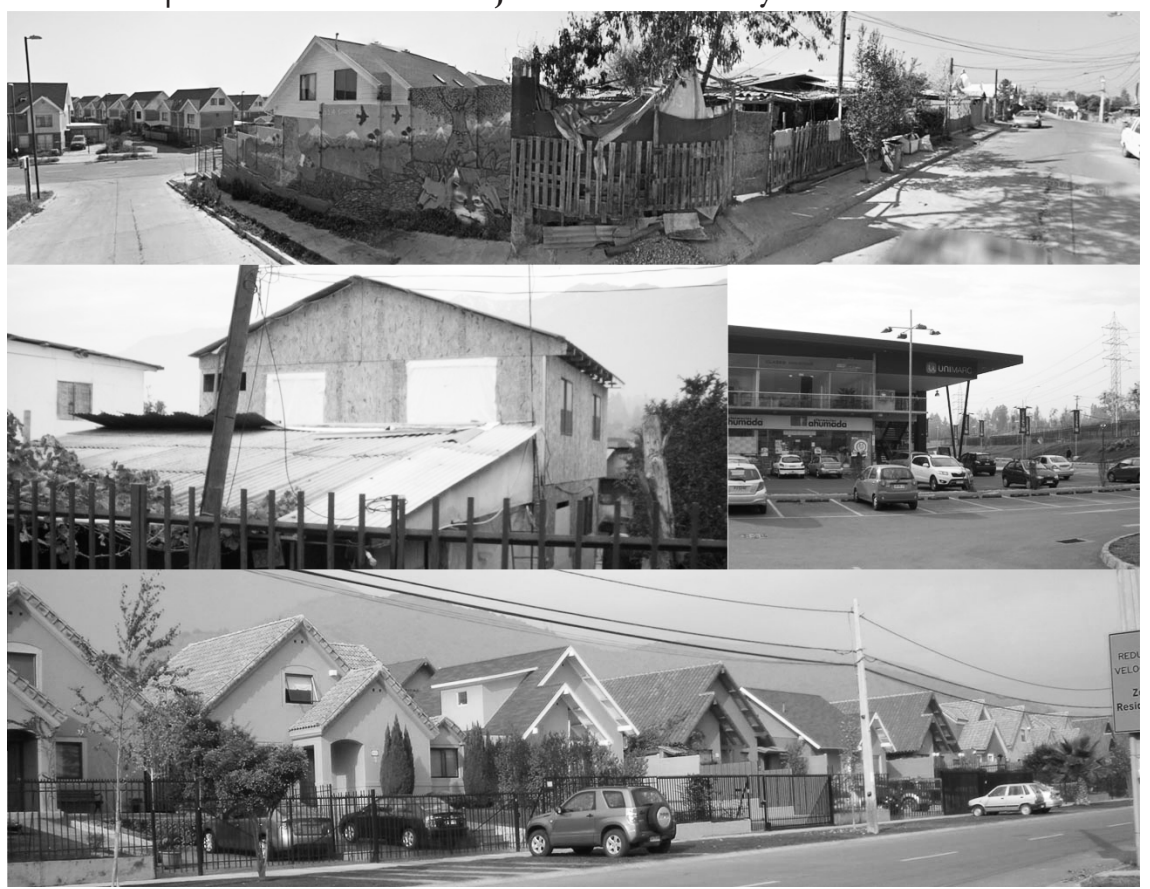

FUENTE FOTOS DEL AUTOR

Este artículo está basado en cinco meses de trabajo cualitativo en terreno, entre mayo y septiembre de 2013. Se utilizaron tres tipos de fuentes de información: i) cincuenta entrevistas con habitantes de clase baja, clase media-alta y actores institucionales del barrio; ii) notas de observación en varios espacios de encuentro intergrupo, y iii) "inventarios espaciales" donde se localizaron y mapearon los rastros de la presencia simbólica de cada grupo (véase Anexo, secciones 3 y 4, para más detalles). 
CUADRO I | Resumen del cambio sociodemográfico, 2002-2013

\begin{tabular}{|l|c|c|}
\cline { 2 - 3 } \multicolumn{1}{c|}{} & $\mathbf{2 0 0 2}$ & $\mathbf{2 0 1 3}$ \\
\hline Población total & 8.871 & 10.656 \\
\hline Área (hectáreas) & \multicolumn{2}{c|}{133,11} \\
\hline Densidad (hab/há) & 66,65 & 80,07 \\
\hline Extrema pobreza & $3,70 \%$ & $2,70 \%$ \\
\hline Pobres & $18,00 \%$ & $14,80 \%$ \\
\hline Clase media-baja & $18,40 \%$ & $15,90 \%$ \\
\hline Clase media & $34,60 \%$ & $33,70 \%$ \\
\hline Clase media-alta & $25,30 \%$ & $32,90 \%$ \\
\hline
\end{tabular}

FUENTE INFORMACión CENSAL Y ESTIMACIÓN 2013 (VÉASE ANEXO, SECCión 2)

\section{Oportunidades: trabajo y educación}

JRT: ¿Hay asesoras del hogar que sean de otros barrios?

ANGÉLICA: Sí, sí. Si uno ve en la mañana, la micro... y bajan cantidad de asesoras, de diferentes partes...

JRT: Ah, no es que todas sean...

AngÉLICA: No, no. Incluso mucha gente que vive en la villa, trae su asesora...

La mayoría de los habitantes de bajos ingresos tiene empleos de servicio doméstico, comercio de baja escala, oficios para el intercambio y empleos de baja calificación, tanto dentro como fuera del barrio. La cita a Angélica, quien trabaja en un local comercial en la casa de su hermana en La Loma, refleja dos cosas. Por un lado, que tal como otras investigaciones han mostrado para casos similares (Sabatini \& Salcedo, 2007; Salcedo \& Torres, 2004), existen oportunidades para trabajar en el servicio doméstico. Y esto significa una ganancia para ambas partes: los trabajadores gastan menos tiempo en traslado, y los empleadores se ahorran el pago del transporte. Pero, por otro lado, hay varios matices que ponen en cuestión los beneficios de la proximidad social. Primero, como señala la cita, muchas empleadas domésticas que trabajan en el barrio vienen de otras áreas de Santiago. Segundo, muchas trabajadoras residentes en el área tienen sus empleos fuera del barrio. Y esto se produce no solo porque haya más empleo afuera, sino por su preferencia personal. Muchas trabajadoras dicen preferir emplearse en el barrio alto por un mejor estatus, un mejor sueldo o un mejor trato. Aquí vale la pena recordar que la clase alta es heredera de una relación más cercana entre patrón y campesinado, debido a que las posiciones sociales estaban estrictamente establecidas. En cambio, la clase media, llamados "siúticos" por la elite, toma la explotación como un símbolo de estatus (Contardo, 2012). Josefina, dirigente de Villa Raúl Silva Henríquez, describe estas situaciones: 
Son muy pocas las que trabajan aquí. Muy poquitas. Yo diría son contadas con los dedos... todas trabajan en La Dehesa, en Las Condes, Vitacura. Yo también trabajé toda mi vida allá arriba. Yo, ahora ni nunca... mire cómo soy... yo no le trabajaría a gente así [refiriéndose a la clase media].

Tercero, existe cierta reticencia en la clase media para contratar vecinos de bajos recursos. Y esto tiene que ver con una desconfianza general hacia ellos, y con la necesidad de establecer una distancia social y física más grande con sus empleados, similar a lo que Sabatini (1999) llama "adolescencia urbana”. José, un residente de clase media que se atreve a criticar a sus vecinos, retrata esto.

...es muy difícil que esa persona contrate (...) a alguien de acá, por el prejuicio. Una, que está cerca de donde vivo yo (...). Otra, que supuestamente no está a su nivel socioeconómico, sociocultural, para entablar relación con ellos... O sea, si la persona... si yo vivo aquí (...) y mi empleado vive en La Pincoya... para mí supuestamente ese es un empleado ideal, porque vive lejos de mi entorno... Yo solamente me relaciono con él laboralmente...

Cuarto, muchos hogares de clase media no tienen servicio doméstico, como lo describe Catalina (clase media), de Villa Parque Las Mercedes.

Por lo menos lo que yo tengo entendido, toda esta cuadra, cada uno se las arregla... Es que, si tú piensas, es una villa-dormitorio... que salen todos a las 7 de la mañana y llegan todos a las 8 de la noche. Y los que tienen nińos, parten con los críos chicos, se los llevan. Entonces no se queda nadie. Entonces creo que es con pinzas, o contados con los dedos, la gente que tiene empleadas.

Y quinto, las posibilidades de encontrar empleo doméstico en el barrio son diferentes entre los distintos asentamientos de vivienda social. Dependen mucho de la cohesión interna en estos conjuntos y de las redes sociales que se establezcan. En el caso de La Loma, la circulación de datos y referencias de empleo doméstico es mucho más dinámica y efectiva que en las villas Carlos Witting y Raúl Silva Henríquez.

Otro de los temas destacados por la literatura existente (Salcedo \& Torres, 2004) se refiere a los beneficios que acarrea en los barrios socialmente diversos, el hecho de tener clientes de mayor poder adquisitivo para los comercios de baja escala (en las propias viviendas sociales). Pero este argumento también está mediado por varios matices. Primero, en la gran mayoría de los barrios pobres se puede encontrar este tipo de establecimientos (a juicio de los entrevistados), por lo que esto no es una característica única de barrios socialmente diversos. Segundo, varios habitantes de clase media tienen locales comerciales en sus propias casas. Por ejemplo, en la calle Jardín Alto, en un espacio de tres cuadras (entre Rojas Magallanes y Santa Julia), hay cinco locales comerciales en viviendas que califican para el 10\% más rico de la población. En otras palabras, el comercio de pequeña escala no es patrimonio de la clase baja. Y tercero, muchos habitantes de clase media prefieren no entrar a los espacios de clase baja (lo cual se verá más adelante), por lo que el beneficio económico de la diversidad social no es tan elevado. En general, los niveles de empleo para la clase baja del barrio son bastantes altos, pero esto se relaciona más con el momento económico que vive Chile que con la cercanía a habitantes de mayores ingresos. Muchos 
entrevistados reconocen que "a nadie le falta pega", pero a la vez reclaman por los bajos sueldos y la precariedad laboral, que ha sido el rasgo más característico de la generación de empleo en los últimos años. Además, el empleo para los jóvenes es de baja calidad y entrega pocas perspectivas de movilidad social, por lo que algunos deciden insertarse en el tráfico de drogas. Las figuras 3, 4 y 5, abajo, muestran la variación del desempleo, el trabajo doméstico y el trabajo por cuenta propia, respectivamente. Tal como se puede observar, los cambios observados responden más a tendencias generales ${ }^{1}$ del Gran Santiago que a una especificidad del barrio.

\section{FIGURA 3 | Variación de desempleados inter-censo}

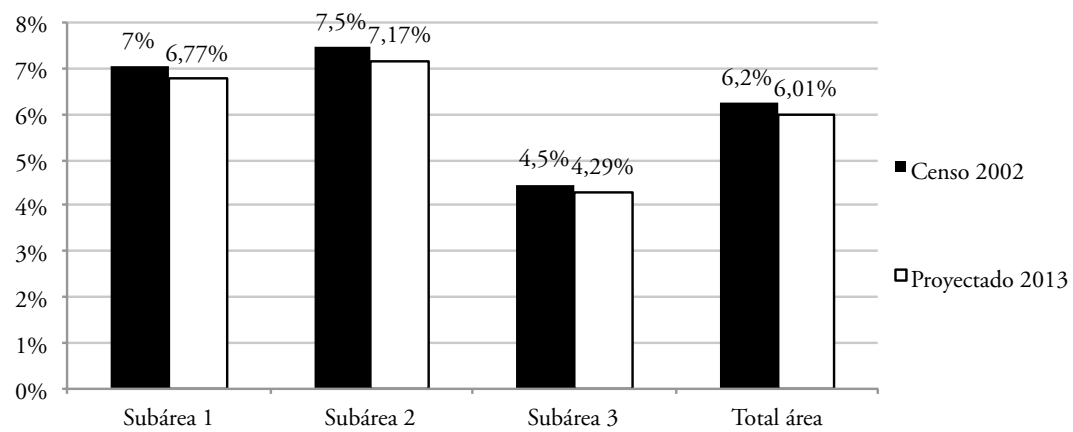

FUENTE CENSO 2002, PRE-CENSO 20 I I Y ENCUESTAS CASEN 2000 Y 2009 (VÉASE ANEXO, SECCIÓN 2)

FIgURA 4 Porcentaje de trabajadores domésticos en el área (estratos más pobres)

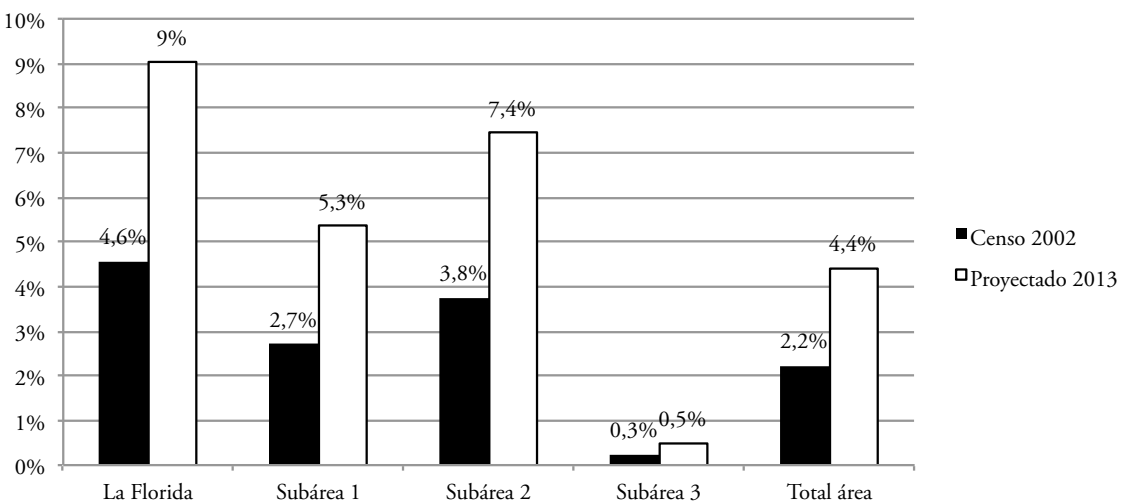

FUENTE CENSO 2002, PRE-CENSO 20 I I Y ENCUESTAS CASEN 2000 Y 2009 (VÉASE ANEXO, SECCIÓN 2)

1 De acuerdo con la encuesta CASEN (véase Anexo, sección 5), el porcentaje de trabajadores domésticos subió de 2,9\% a 4,7\% entre 2000 y 2009, en el Gran Santiago. Asimismo, los trabajadores por cuenta propia subieron de $21,4 \%$ a $25,5 \%$ en el mismo periodo. 
FIGURA 5 | Variación del porcentaje de trabajadores por cuenta propia

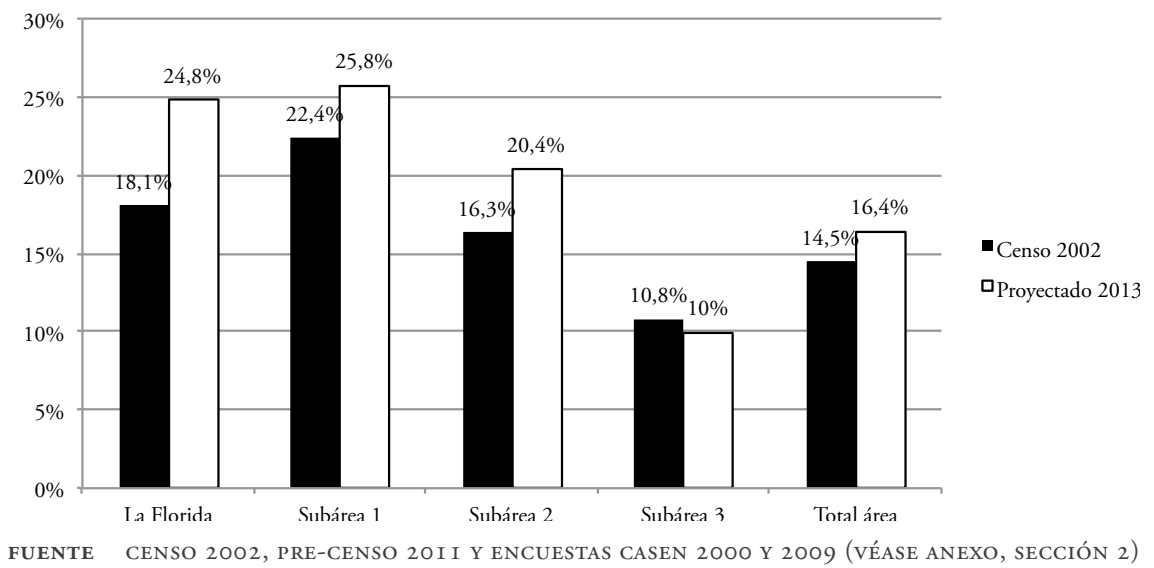

Respecto de oportunidades de educación, tanto las posibilidades que el barrio otorga para la movilidad social como las relaciones entre grupos, están limitadas por la fuertísima segregación escolar de nuestro país. La mayoría de los habitantes del sector tiene a sus hijos en doce establecimientos: cuatro escuelas municipales gratuitas, cinco colegios particulares subvencionados (que cobran desde 25.000 a 100.000 pesos mensuales) y tres colegios particulares pagados (que cobran más de 100.000 pesos mensuales). En términos de calidad, el puntaje promedio SIMCE (Sistema de Medición de la Calidad de la Educación) ${ }^{2}$ (octavo básico: lectura y matemáticas) del sector por dependencia es el siguiente: 248 puntos en municipales, 267 en particulares subvencionados, y 276 en particulares pagados, mientras que el promedio nacional es de 242, 262 y 305, respectivamente. La fijación de aranceles, principal herramienta de segregación socioeconómica, se realiza de manera bastante arbitraria, según explica Gonzalo, administrador de un colegio particular subvencionado.

JRT: ¿Cómo definen en este colegio el costo de la mensualidad? Usted me dice que está entre 40 y 70 mil... ¿será por el barrio, por el nivel de ingreso?

GonZalo: No, no hay nada científico como eso, nos guiamos más bien por la competencia... es lo que cobra el resto de los colegios (...) pero no he hecho ningún análisis de las posibilidades de pago de nadie. Suponemos que todos pueden pagar eso, porque todos cobran lo mismo...

De esta manera, la segregación escolar divide a las familias del barrio entre los distintos establecimientos. De la clase baja, la mayoría asiste a escuelas municipales y algunos a particulares-subvencionados, mediante una beca del Estado. Pese a ello, dichos establecimientos solo reciben entre $10 \%$ y $15 \%$ de alumnos con beca. De los residentes de clase media, todos asisten a colegios particulares subvencionados y particulares-pagados. Y lo más importante aquí, es que dichos residentes naturalizan 
la segregación escolar como algo normal, como lo muestra Carolina, residente de clase media.

JRT: ¿No hay tantos niños de La Loma en esos colegios?

Carolina: En esos colegios de acá no. No, porque ellos tienen un colegio municipalizado, el de Lo Cañas, tienen bus, que es básica... y después pasan al Elsa Santibáńez. Y tienen otro técnico, el Benjamín... Vicuña. Está en el [Paradero] 14; entonces de ahí, se trasladan pa’ allá. [Énfasis añadido]

Es en los colegios particulares subvencionados donde se dan los mayores niveles de mezcla social. Sin embargo, hay algo de discriminación hacia los niños de clase baja (se les dice despectivamente "los lomitos" a los de La Loma), y los padres de clase media tienen muy baja participación e involucramiento. Un ejemplo contrapuesto lo presenta un jardín infantil que existe en La Loma, el cual fue autogestionado y formalizado por sus organizaciones. A este establecimiento asisten algunos niños de clase media, pero a muchos los mandan en transporte escolar (pese a que la distancia es mínima), y algunos padres han preferido enviar a sus empleadas a las reuniones. La escuela en este barrio funciona, entonces, como uno de los mecanismos más severos de segregación entre sus residentes. Como señalara el diputado Carlos Montes al entrevistarlo: "La escuela era clave (...) y el financiamiento compartido lo mató (...) provocó una segregación, una segmentación brutal”.

\section{Relaciones entre grupos y clasismo}

...ellos creen que son exclusivos, que son profesionales... por ser dueńos de autos, dueños de esto... Entonces hay mucha cosa negativa de parte de ellos hacia nosotros (...) o sea, ellos se expresan "los delincuentes de La Loma". (Agustina, habitante de La Loma)

Los habitantes de clase baja en el área de estudio sienten una discriminación generalizada por parte de la clase media. Las relaciones de intercambio funcional entre grupos no alcanzan a tener una importancia significativa de socialización. Como dijera Louis Wirth (1927) refiriéndose al clásico gueto judío, "las relaciones comerciales son posibles cuando ninguna otra forma de contacto entre dos personas puede ocurrir" (p. 60). Benjamín, uno de los fundadores de La Loma, describe su situación personal.

Mire, voy a decirle la verdad: no me relaciono con nadie yo. Pa’ qué voy a mentirle (...) trabajo con la gente... pucha, con Jardín Alto, por acá, por allá, pero no me relaciono con ellos (...) tengo gente que ellos me consideran amigo a mí. De las villas. "Usted es mi amigo", me dicen (...) [pero] nos conocemos tan poco...

Si se observan los grupos separadamente, se vislumbran otros detalles. Los asentamientos de bajos recursos presentan una importante cohesión social por su trabajo para establecer y mejorar los distintos conjuntos habitacionales, y por las necesidades de constituir lazos de subsistencia. El barrio es de gran importancia para ellos, y en gran parte sus redes sociales están circunscritas a este territorio. Pero la clase media de este barrio es caso aparte. Uno de los temas más impactantes de esta 
investigación es la fuertísima apatía, desconfianza y falta de participación de la clase media. Pese a que llevan varios ańos viviendo en este sector, el nivel de conocimiento mutuo entre residentes es bajísimo y el nivel de confianza es casi nulo, aunque sus vecinos sean del mismo estatus. La única fuente de lazos comunitarios está en las distintas escuelas, pero al ser estas "comunidades flotantes" sin apego local, casi no hay intersección con un grupo territorial que las identifique. La gran excepción son los dueńos de locales comerciales de clase media, quienes tienen una relación cotidiana con los clientes del barrio. Pero la gran mayoría vive una vida aislada, sin amigos ni incentivos para pasar su tiempo libre en el barrio. Rafael, residente del condominio Llanos de Lo Cańas, pese a dirigir algunos asuntos domésticos del condominio, tiene esa sensación.

... los vecinos son... no hay una relación así, digamos... que hay ciertas actividades en conjunto entre vecinos, que se vayan a visitar, no, no. Cada uno mantiene su vida de forma independiente con su propia gente... respetándose mutuamente, pero no hay una relación social de amistad interna, ni instancia de comunicación (...) uno conoce a alguna gente más que otra, pero no es una red social que esté apuntando a ningún objetivo...

Esta falta de organización se revierte cuando los habitantes de clase media ven amenazada su propiedad. Algunas veces reaccionan de forma individual, poniendo más rejas o recurriendo al Municipio, pero otras veces se organizan. Los temas que han logrado movilizarlos han sido principalmente la seguridad y la mantención de espacios públicos. Dos eventos han podido generar uniones de mayor calibre en este sector, aunque con objetivos y medios contrapuestos. Por un lado, ante la colocación excesiva de antenas para telefonía celular, recurrieron a la Junta de Vecinos de La Loma para tener un mayor impacto en el Municipio. Pero, por otro, ante la incipiente construcción de más viviendas sociales, llegaron a influir hasta altas esferas del Ministerio de Vivienda para congelar el proyecto, lo cual se presentará más adelante.

Las relaciones entre clase baja y clase media también se pueden observar desde las situaciones más opuestas. Se pudo constatar la existencia de algunas organizaciones con participación transversal, como un grupo de adultos mayores y un grupo de matrimonios ligada a la Iglesia. Francisca, habitante de clase media-alta residente en Jardines de la Viña, representa este contrapunto. Ella y su esposo son profesionales y viven con dos hijos que van a la universidad. Participa con su marido en el grupo de matrimonios mencionado, y lo describe como una de las experiencias más importantes para su vida. Ahí tiene relación con mucha gente de La Loma y le ha servido para sacarse el miedo y los prejuicios. Sin embargo, cuando hay hechos específicos de delincuencia, la mayoría de habitantes de clase media culpa inmediatamente a los vecinos de bajos recursos y se estigmatizan sus espacios.

\section{Clasismo y diferenciación social}

... la gente de Jardines de la Viña son tan siúticos (...) el perfil de esta gente de al lado es... El profesional joven que normalmente viene igual de estatus bast... eee... medio... medio, medio-bajo, pero que ha podido surgir y se compra inmediata- 
mente el tremendo coche... (Isidora, clase media-alta. Vive en Lo Cañas y trabaja en la Red de Defensa de la Precordillera)

El clasismo en Chile ha sido muy poco estudiado, pese a que se habla abiertamente de ese rasgo y que pareciera ser la mayor fuerza divisoria de nuestra sociedad (así como es el racismo en otros contextos). Es decir, se da por sentada su existencia (véase Sabatini, Rasse, Mora \& Brain, 2012), pero no se profundiza mayormente en sus componentes históricos, ni en sus mecanismos de aplicación. El clasismo es un sistema de mecanismos simbólicos para definir pertenencia a grupos, bordes y distancias sociales. Sin importar lo políticamente incorrecto que sea, el clasismo opera contra la meritocracia, de modo de reproducir un régimen de tendencia oligárquica y de extremas desigualdades sociales (Contardo, 2012). La cita de Isidora (arriba), muestra tanto el desprecio a la clase media que la elite considera "arribista", como una implícita descripción de cómo se relaciona la clase media con la clase baja.

Si en la clase media de este barrio abundan la apatía y la desconfianza, ¿por qué entonces vivir en un lugar así? Rafael, residente de un condominio cerrado, se refiere a esto.

...yo creo que la gente busca a sus pares, y no hay muchos puntos en común... o sea, no veo por dónde pueda haber una forma de relacionarse mejor... hay necesidades distintas, hay objetivos distintos... [Énfasis ańadido]

Decir que "la gente busca a sus pares" suena casi como para el título de este artículo, si no fuera porque su trasfondo es altamente cuestionable. Primero, ya se ha descrito que hay una muy baja socialización entre aquellos "pares" de clase media. El mismo Rafael seńala el bajísimo nivel de las relaciones sociales en su propio condominio. Y segundo, si los residentes de clase media tuvieran la opción de irse al barrio alto por el mismo precio, dejarían a sus "pares" sin remordimiento alguno. Es decir, no hay un apego al barrio ni como espacio físico, ni como espacio social. ¿Qué queda entonces? El simbolismo de la localización; el estar en el lugar geográfico y junto a los vecinos de mayor estatus posible. El valor simbólico de los "pares" permite que el barrio actúe como pantalla para la afirmación del estatus. Y no se necesitan relaciones vecinales para ello. Entonces, el barrio para la clase media no tiene importancia funcional, sino principalmente simbólica, similar a lo que Savage (2010) llama “pertenencia electiva”.

Las distinciones de clase operan de manera muy compleja, y en el curso de esta investigación fue muy difícil descifrar un "aspecto de clase". Se cruzan aquí color de piel, vestimenta, presentación y expresión corporal. Entonces, frente a las pocas diferencias físicas y en el contexto de un masificado acceso al consumo, se hace muy difícil saber "quién es quién" en este barrio, lo cual pone una extrańa nebulosa sobre la discriminación de clase. Eduardo, habitante de clase media en Villa Parque Las Mercedes, deja entrever este problema.

JRT: Y usted en el colegio (...) ¿se encuentra con gente de La Loma?

EdUARDo: Eh... es que sabe, cuesta...

JRT: ¿Cuesta verlos?

Eduardo: Claro, cuesta... ¿cómo decirte?... decir "este sí y este no”. 
JRT: Mm... ¿difícil ubicarlos?

EdUARdo: Claro, difícil... porque van igual vestidos de buena manera...

El elemento que sí marca las diferencias, y que se transforma en una herramienta de clasificación en contextos de diálogo, es el estatus ocupacional. Humberto, residente de clase media-alta en Jardines de la Viña, detalla muy bien esta diferenciación.

Aquí hay un entorno que está más o menos consolidado (...) son casas que no son baratas... en donde la mayoría de las casas tienen dos autos para arriba... tienen buenos trabajos, buena situación económica, la mayoría... lo cual no quiere decir nada, pero sí hay una formación distinta en esos hogares... será el 85\% 90\% de las personas, del conjunto de familias que, no sé... mamá, papá profesionales, que tienen hijos que quieren que sean profesionales...

Ahora bien, dado que la vivienda en Chile es mayoritariamente en propiedad (en todos los niveles sociales), la principal marca de diferencia entre clases, en ausencia de diálogo (lo que ocurre en la mayoría de los casos), es la calidad de la vivienda y la urbanización. Ello es así a tal punto, que algunos estudios de marketing usan la fachada y el entorno de la vivienda para obtener la aproximación más exacta al nivel socioeconómico de sus habitantes (ej.: "la vivienda no miente"). Y en este contexto, las diferencias de calidad se transforman en fuente de miedo, diferenciación y restricción espacial. José, habitante de clase media, describe cómo el estándar de la vivienda y del barrio es la fuente primaria de representación y conocimiento para "el otro".

...tú te vas dando cuenta en el camino, de que hay una diversidad bastante gran-

de... o sea, es cosa de que tú te des... tomes tu auto, vayas una cuadra hacia arriba, $\mathrm{y}$ vas a ver otra realidad que es totalmente diferente...

De alguna manera, esto también tiene que ver con un sustrato racial, que tiene poca relación con lo físico y está más vinculado con un prejuicio acerca de las costumbres étnicas. Consultados acerca de su posición entre europeos e indígenas, los habitantes de clase media se identifican más con lo europeo o simplemente con lo chileno, reafirmando el "mito del mestizaje", como señalan algunos autores (Alvarado \& Fernández, 2011; Waldman, 2004). En cambio, los habitantes de bajos recursos se identifican fuertemente con lo indígena, y específicamente con lo mapuche, haciendo referencia a su pasado rural reciente. Así, el clasismo y el racismo contemporáneos tienen un elemento en común muy importante: es muy difícil reconocer su manifestación de manera abierta y nadie reconoce que lo practica. Varios habitantes de clase media seńalan la existencia de mucha discriminación, pero a la vez se autodefienden contradictoriamente diciendo que ellos no son clasistas ni racistas. Eduardo, habitante de clase media en Villa Parque Las Mercedes cae en este tipo de contradicción.

No, no tengo esa discriminación... ni por los rubios, ni por los negros. No soy ese tipo de persona que te puede discriminar por el color. Porque nosotros los chilenos somos racistas, somos terribles. Pero yo, afortunadamente no. Lo que sí, no me casaría con una negra... a lo mejor... no, no... No es mi gusto. Pero no, no soy así. 
El elemento histórico del clasismo en la clase media ha sido ocultar el origen social, en un cuidadoso despliegue escénico destinado a lograr la aceptación de la elite (Contardo, 2012). Al ser consultados por la comuna de residencia anterior a La Florida, los habitantes de clase media dan respuestas confusas y vagas, dejando entrever su preocupación por "no mostrar la hilacha". Pero en una actitud minoritaria dentro de esta corriente, una clienta de clase media (anónima) en un pequeño local comercial ubicado en un conjunto de vivienda social, explica por qué a ella no le da vergüenza comprar en estos almacenes. A diferencia de sus vecinos, no le molesta reconocer abiertamente su origen social, y sentirlo como suyo y convivir con él.

Sabes lo que pienso yo (...) que todos venimos de una raíz, y esa raíz es acá (...) porque salimos de acá. Entonces, al final nos sentimos cómodas comprando en este negocio (...) ¿̨por qué venimos acá de diferentes partes?... Porque la raíz nuestra es acá...

Tal como se mencionara antes, la organización más relevante de vecinos de la clase media-alta se produjo por una masiva oposición a la construcción de un nuevo proyecto de vivienda social en las cercanías del área de estudio. El proyecto de Las Tinajas, cuyo terreno fue comprado por el Servicio de Vivienda y Urbanización (serviu) en 2009, está destinado a familias de La Florida y buena parte de los beneficiarios son familias jóvenes de La Loma. Sin mucho ruido mediático, los habitantes de clase media-alta han puesto presión en todas las partes del proceso, llegando incluso a mantener congelada la decisión del Ministro de Vivienda y Urbanismo. Un posteo en el sitio web reclamos.cl, describe la posición de estos vecinos.

No compres tu CASA en Jardines de la Viña, proyecto ubicado en Av. La Florida [sic, es Rojas Magallanes] con El Hualle. Prontamente se construirán viviendas sociales en parcelas colindantes a los condominios. La constructora e inmobiliaria no informaron de esta situación cuando compré en verde hace casi un año, sabiendo estos últimos de la situación. Si compras, se te desvalorizará tu propiedad, existen riesgos altos de delincuencia, tendrás que levantar muros, y poner protecciones en puertas y ventanas. Resultado, lo que compraste como un proyecto de vida, se va a las pailas... por una constructora que no entrega la información correcta.

Los habitantes de clase media-alta organizaron una reunión y solicitaron para ello la sede de la Junta de Vecinos de Lo Cańas. Pero los dirigentes de dicha junta de vecinos, que tienen muy buena relación con dirigentes de bajos recursos, invitaron a otros actores a la reunión; entre ellos, a la dirigente de la Unión Comunal de Allegados, al diputado Carlos Montes y a dirigentes de La Loma. Isidora, representante de la Junta Vecinos de Lo Cañas, relata esta situación con desprecio a sus vecinos de clase media-alta.

¡Tremenda alarma po’! ¿Cómo iba a venir toda esa “chusma” a vivir allá? (...) Hicimos la reunión ahí, y llegó en esa reunión [el diputado] Montes con la presidenta de la Asociación de... de Allegados y con varios pobladores... Y esta "chusma" de al lado [vecinos de clase media-alta] decía así: "Nosotros no queremos que esta 
'chusma' [habitantes de clase baja] venga a vivir al lado de nosotros. ¡Nuestros hijos no van a poder ir a la calle! ¡Vamos a andar con miedo de que nuestros hijos vayan a ser violados en la misma calle! ¡Y ahora está lleno de borrachos y drogadictos!”. ¡Delante de esta gente! ¡Yo me moría de vergüenza!

La separación entre clase media y clase baja tiene sus raíces en el clasismo histórico; en la necesidad, por parte de la clase media, de renegar de sus orígenes humildes y utilizar la explotación a la clase baja como símbolo de estatus (Contardo, 2012). Con tal trasfondo, las políticas neoliberales han significado un nuevo aporte a la fragmentación de la sociedad chilena. Es verdad que numerosos estudios sobre estratificación social en Chile (Contreras, Cooper, Herman \& Neilson, 2005; Espinoza \& Barozet, 2009; Torche, 2006) muestran los variados aspectos que la clase media comparte con la clase baja: niveles similares de movilidad social, vulnerabilidad, capacidad de consumo, y hasta el tipo de habla. Sin embargo, la clase media percibe una diferencia fundamental con la clase baja: una mayor desprotección por parte del Estado. La focalización de recursos y servicios estatales en los sectores de menores ingresos o más vulnerables (Raczynski, 1994) ha aportado a un mayor fraccionamiento entre clase media y clase baja, generando así cortes discretos entre pobres y no-pobres, y grandes contrastes entre lo público y lo privado. Entonces, las enormes diferencias de calidad, a las que se suma el sentimiento de desprotección, crean una fuerte reticencia en la clase media a utilizar o visitar los espacios y servicios subsidiados para la clase baja. Juan, habitante de clase media en Villa Parque Las Mercedes, retrata este particular resentimiento.

En realidad nosotros, eh... ahí en La Loma también hay... pero es clase media hacia abajo, hay gente de esfuerzo también, y otra gente que están acostumbrados a que les den todo. Igual acá afuera, en esta vi... usted, no sé... cuando uno pasa se nota altiro, si usted no se... ¿̧ha subido hacia... [La Loma]? [Énfasis añadido]

\section{Seguridad y espacio público}

Catalina, habitante de clase media en Villa Parque Las Mercedes, no se sintió nada cómoda cuando se le solicitó una entrevista. Se le dijo que una dirigente con la cual trabaja había dado su teléfono, y una de sus primeras reacciones fue decir solapadamente: "La voy a llamar pa' penquearla". Al llegar a su casa, al frente de su puerta había un auto de seguridad privada estacionado, con una persona sentada adentro. Durante la entrevista, su lenguaje había cambiado y después de cada frase, Catalina repetía continuamente la palabra “¿catchái?”, pronunciado del modo en que lo hace la clase alta chilena. Al salir de la entrevista, el auto de seguridad todavía estaba afuera. Al poco rato, se escuchó a Catalina salir de su casa a hablar con el chofer del auto: “¡Ya no me raptaron!”, le dijo con alivio.

El temor a la delincuencia es la principal inquietud de la clase media, y hace que la desconfianza llegue a un extremo. Básicamente, sus miembros conocen muy poca gente, no confían en nadie y -para ellos- cualquiera podría ser un criminal. Francisca, habitante de clase media-alta en Jardines de la Viña, dedicó varios minutos de la entrevista a describir un intenso episodio que le ocurrió con su hijo de dieciséis 
años. Este había bajado corriendo por Rojas Magallanes para alcanzar el bus, y súbitamente un hombre de otro condominio lo atrapó y lo inmovilizó. El hombre le dijo: “¿De dónde vienes robando 'hueón’?, ¿de dónde vienes arrancando?”, a lo cual su hijo le respondió: "No, si no vengo robando". El hombre lo tiró al suelo, diciéndole: “№ 'hueón’!”. Para mala suerte del hijo de Francisca, justo venía pasando un vehículo de la Policía de Investigaciones. El hombre detuvo el vehículo, diciendo a sus ocupantes: “¡No, a este 'hueón' lo encontré robando, estaba robando!”. Afortunadamente, dice Francisca, luego pasó un furgón de Carabineros, lo cambiaron de vehículo y como su hijo estaba sin carnet de identidad, lo llevaron a su casa para constatar domicilio. Al darse cuenta de lo que había pasado, Francisca salió con su hijo a buscar al hombre que lo había incriminado. Lo encontraron en el supermercado y ella descargó toda su rabia contra él. La conclusión de Francisca fue que dicho personaje "andaba viendo delincuentes por todos lados".

Los habitantes de clase media gastan muchos recursos en seguridad; algunos incluso manifiestan la voluntad de irse del barrio e inculpan a los vecinos de clase baja cada vez que ocurre algún incidente. Berta y su hermana Angélica, ambas de La Loma, describen esta persistente inculpación.

Berta: ... igual nos discriminan a nosotros. Nos discriminan mucho porque igual...

AngÉLICA: ... todo lo que pasa ponte tú...

BERTA: ... roban en una casa...

Angélica: “¡Los de La Loma fueron!”. O, “creo que asaltaron la Farmacia Ahumada. Creo que eran los de La Loma”. ¿¿Me entiende o no? Entonces todo es ¡nosotros, nosotros, nosotros!...

Además, hay variados elementos externos al barrio que han aumentado la desconfianza de la clase media en un contexto de baja socialización: los escándalos de abuso sexual y de violencia intrafamiliar, y la explotación mediática de la delincuencia. "Hay tanta cosa que anda pasando allá afuera", dicen muchos. Para la clase media, entonces, la construcción del miedo está relacionada con su discriminación y prejuicio contra sus vecinos de bajos recursos, y con su casi nula cohesión interna, lo que a su vez aumenta su propensión a construir realidad desde historias externas (como los noticiarios de televisión). La comparación de estas percepciones con los niveles reales de delincuencia en el barrio apoya este argumento. En el área de estudio, el índice de delitos de mayor connotación social (DMCs) por cada mil habitantes ha tenido un promedio 16,9 en los últimos cuatro años (figura 6, véase también Anexo, sección 6), mientras en el Gran Santiago fue de 22,2; y en La Florida, de 37,8.

La percepción de delincuencia es absolutamente contrapuesta entre los habitantes de bajos ingresos. Para ellos, el barrio es muy tranquilo y pacífico, y eso contribuye en gran parte al atractivo de vivir ahí. Esteban, suboficial de la Tenencia de Carabineros Los Jardines de La Florida, comparte esta percepción.

Nuestro sector, específicamente, no es un lugar peligroso, no es un lugar conflictivo. No es un lugar como pa' que la gente ande con miedo... a que en cualquier... 
No, no es así. Los delitos que se realizan, como le dije, son realizados por gente que viene de afuera, pero nada más. La gente puede andar tranquila, digamos salir con sus niños y con su familia, ir a comprar...

Figura 6 | Evolución del índice de DMCs para los cuadrantes 169 y 273 de La Florida

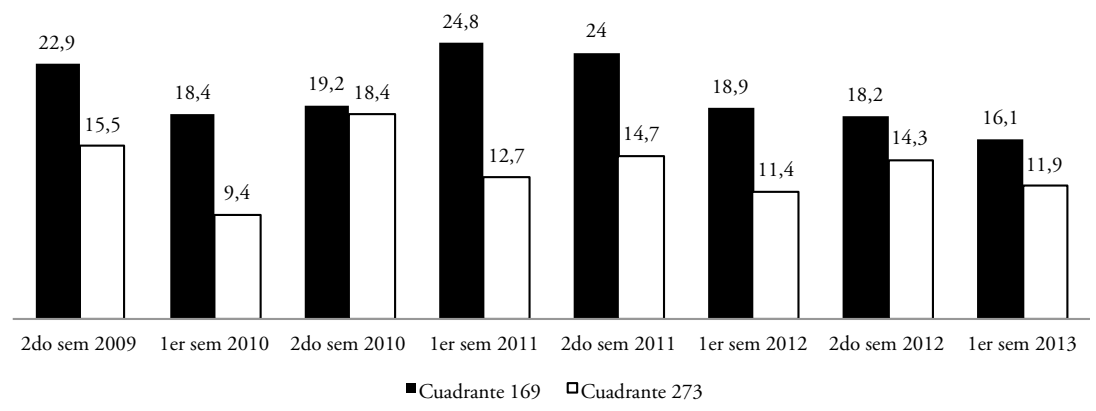

fuente elaboración propia a partir de datos de Carabineros de Chile

Respecto al uso del espacio público, y como se puede deducir de la discusión anterior, los habitantes de bajos recursos desarrollan su socialización en el barrio y ocupan frecuentemente sus espacios públicos. Los habitantes de clase media, por el contrario, viven mayoritariamente dentro de su casa o salen fuera del barrio, debido a que sus redes sociales no tienen base territorial. Alejandra, quien vive en un condominio cerrado en calle Araucanía, describe estas situaciones.

Yo no hago muchas cosas en el barrio, sinceramente. Casi todo lo hago lejos... solo cosas puntuales (...). Y cosas simples. Onda mi mamá va a la peluquería de Nuñoa, o vamos al supermercado del Florida Center, que está dentro de la comuna, pero igual no es como que te quede cerca.

Entre los pocos espacios "públicos” que ocupa la clase media están las áreas verdes insertas dentro de los condominios cerrados, los cuales no permiten acceso a habitantes externos. Sin embargo, la mantención sigue corriendo por cuenta del Municipio, lo que representa una privatización sin responsabilidades. Rafael, del condominio Llanos de Lo Cañas:

Rafael: El Municipio manda un par de tipos, pero que no sirven mucho. Nosotros tenemos nuestros propios jardineros...

JRT: Ya, y por ejemplo, la cuenta del agua, ¿̨la pagan ustedes?

Rafael: Nosotros pagamos el... no... la luz de la caseta, son nuestras... el agua, los espacios comunes, los paga la Municipalidad. Pero no nos aporta mucho tampoco...

Respecto del tránsito entre espacios, la clase media no visita ni transita por los espacios de clase baja, pero la clase baja sí pasa por los espacios de clase media, con 
excepción de los condominios cerrados. A algunos habitantes de clase media-alta les preocupa la circulación de individuos de clase baja cerca de sus casas. Humberto, habitante de un condominio cerrado en Jardines de la Viña, describe esta situación desde una dudosa lejanía.

Hay una obra que se está haciendo aquí, que yo te digo que a muchos les ha complicado... porque complica mucho el tema de Las Tinajas (...) y aquí circula toda la gente que viene llegando y se va yendo en la tarde a la obra... y yo te digo que a mucha gente le molesta, o sea... no sé po', aquí en el condominio tú no ves gente que ande caminando y tirando escupos en el piso... pero afuera sí po'...

Pese a la alta preocupación por la delincuencia y la seguridad, los habitantes de clase media en general no evaden individuos en las calles, debido a la difícil diferenciación de un "aspecto de clase". Lo que sí hacen, y de lo que sí están seguros, es discriminar y evitar los lugares de la clase baja, como La Loma, y las villas Carlos Witting y Silva Henríquez. Rafael, del condominio Llanos de Lo Cañas, es bastante sincero en esto.

JRT: O sea, ¿̨usted nunca ha entrado a La Loma, ni tampoco ha pasado...?

Rafael: No, ni se le ocurra. Sí he entrado. He entrado en auto por alguna casualidad, pero... o sea... no voy a entrar caminando, ni vamos a entrar... o sea, yo creo que nadie acá lo hace...

JRT: ¿¿Ni tampoco pasar por Marcela Paz [Villa Silva Henríquez]?

Rafael: No, o sea, a veces uno... o qué se yo. De repente hay algunas personas que hacen algunas "peguitas" o uno quiere buscar a alguien que... una modista o un zapatero, pero va y vuelve... e incluso creo que muy poco (...). No es que haya un tránsito o un conocimiento. No, no creo. Uno va a comprar lo que tiene que comprar, si está cerca... y nada más... y vuelve a su lugar...

Además, las plazas y los parques del área de estudio son demasiado pequeños y no ofrecen actividades para su animación. Como contrapunto, los grandes centros comerciales, el espacio "público” por excelencia en La Florida (De la Jara, 2003), concentran toda la recreación y el comercio.

Por último, varios problemas se han presentado en el uso del espacio público en el área de estudio. Primero, se ha construido un par de muros de separación alrededor de La Loma. Segundo, varias calles se han construído sin salida, siendo que por Plan Regulador debieran tener continuidad. Y por último, los mismos condominios cerrados se convierten en áreas de acceso restringido, incluso para los habitantes de clase media que pertenecen al condominio, pero cuya vivienda está orientada hacia una calle externa.

Para finalizar, un comentario acerca del enrejamiento. Sabatini y Salcedo (2007) señalan que "la existencia de muros y rejas es un fenómeno mucho más antiguo que la aparición y propagación de condominios cerrados" (p. 588); que "la existencia de muros es solo una realidad normal" (p. 593); y que las "medidas de seguridad de los condominios cerrados no están dirigidas" (p. 593) a los habitantes de bajos recursos. Cabe reconocer aquí que las rejas existen en todo Chile y Latinoamérica (Roitman, 2011). Sin embargo, lo que ocurre en los condominios cerrados no es lo mismo que 
sucede en otros barrios: por algo se llaman "condominios cerrados". Aquí vale la pena repetir una parte del posteo de los habitantes de clase media-alta en Jardines de la Viña, acerca del futuro proyecto de Las Tinajas: "Existen riesgos altos de delincuencia, tendrás que levantar muros, poner protecciones en puertas y ventanas". Se hace necesario, entonces, distinguir cuáles son las motivaciones de los propietarios para poner rejas y cuáles son los efectos simbólicos para los vecinos o transeúntes. Los cerramientos se usan para protegerse, y el tamańo de la reja generalmente denota qué tan desprotegidos se sienten sus propietarios. Pero las rejas también tienen un efecto disuasorio, como todo aparato de seguridad. Y muchas veces este efecto es más importante que el simple cerramiento físico, constituyéndose en un mensaje específico hacia todos los desconocidos. Y en el caso de este barrio, no solo los habitantes de La Loma y de las villas Carlos Witting y Silva Henríquez son desconocidos. Todos son desconocidos y potenciales "delincuentes" (como el hijo de Francisca), y el mensaje de las rejas y los aparatos de seguridad va dirigido a todos ellos.

\section{Conclusiones}

En función de las cuatro dimensiones de la integración socioespacial, se pueden extraer algunas conclusiones.

En términos de la dimensión física, este caso presenta una alta proximidad entre distintos grupos sociales, reflejando una "diversidad abismante", como lo describiera un funcionaria del Municipio de La Florida. Sin embargo, existe mucho encerramiento, poco uso colectivo del espacio público y un bajo apego territorial en las redes sociales de la clase media. De este modo, la cercanía física en el barrio hace más crítica la segregación en otras esferas de socialización, como la educación y la recreación. Luis, párroco de la Iglesia San José de las Mercedes, resume este problema: "Es posible la diversidad, siempre y cuando existan puntos de contacto. Una diversidad encerrada en los condominios, no me interesa para nada”.

En términos de la dimensión funcional, a pesar de los intercambios de bienes y servicios, muchos habitantes de bajos recursos no sienten los beneficios, enfatizando incluso que "el barrio sería lo mismo con o sin habitantes de clase media". Los grupos de bajos recursos destacan la llegada de nuevos servicios al barrio, pero no lo sienten como suyo y, en ocasiones, terminan usando su propio comercio de autoabastecimiento. Y si bien la llegada de la clase media ha traído algunas posibilidades de empleo para la clase baja, este tipo de empleo solo mantiene el statu quo y las altas desigualdades.

En cuanto a la dimensión relacional, se observa la existencia de una sola comunidad: la clase baja establecida y cohesionada, la cual no se relaciona de manera significativa con la clase media, debido a las divisiones del clasismo y las políticas focalizadas.

Y respecto de la dimensión simbólica, existe una identidad poco definida del barrio; la clase baja siente que los cambios no son para ellos, y la clase media no siente que el barrio es totalmente propio. Además, no existe mucho reconocimiento del valor del "otro", más allá de los recursos que trae la clase media o de la importancia del trabajo que desarrolla la clase baja. 
En resumen, es difícil pensar que exista integración cuando solo una sola dimensión presenta resultados medianamente positivos (dimensión funcional), en un contexto general de fragmentación urbana (M. Pérez, 2011). Y como se ha planteado aquí, los intercambios funcionales no reducen la pobreza, lo cual ya ha sido comprobado en exhaustivos estudios que comparan los efectos socioeconómicos de la mezcla social entre barrios homogéneos y barrios heterogéneos (véase Ostendorf, Musterd \& De Vos, 2001). Tal como Chamboredon y Lemaire (1970) afirmaran décadas atrás (corroborado por Préteceille, 2003), la coexistencia local de grupos sociales diferentes no es garantía automática de mejor integración social, ya que a menudo genera competencia y conflictos.

A partir de estos argumentos se pueden extraer algunas críticas a la literatura existente sobre integración en barrios de condominios cerrados y vivienda social. Primero, se asume la dispersión territorial como vía prioritaria para el mejoramiento de la pobreza (a través de políticas de suelo), en vez de pensar en políticas de redistribución territorial de recursos y oportunidades. Segundo, se asume que los barrios diversos son positivos por los intercambios funcionales, sin tomar en cuenta la persistencia de la segregación y la desigualdad. Y tercero, se propone que el principal problema por resolver es la disposición de la clase media a vivir junto a la clase baja (Sabatini et al., 2012, véase gráfico 7), dejando fuera de la ecuación el problema inverso: la disposición de los más pobres a vivir con vecinos de mayor estatus y, más significativo aun, la importancia que le dan a esa posibilidad. En resumen, el problema presentado en este caso no se limita a la concentración o desconcentración física de la pobreza (y sus efectos de barrio), sino sobre todo a la superposición de variadas órbitas de segregación, estigmatización acumulada y fuerte fragmentación institucional. 


\section{Anexo metodológico}

\section{Figura 1 (derecha): distribución socioeconómica}

A partir del porcentaje de habitantes de cada grupo socioeconómico por manzana (véase sección 2, abajo), se calculó un índice simple de Composición Socioeconómica de la Manzana (CSM) de la siguiente manera:

$\boldsymbol{C S} \boldsymbol{M}=(\% A B C 1 \times 100)+(\% C 2 \times 75)+(\% C 3 \times 50)+(\% D \times 25)+(\% E \times 0)$

Así, una manzana con $100 \%$ de habitantes ABC1 obtiene un índice de 100, una manzana con $20 \%$ de cada uno de los cinco grupos obtiene un índice de 50 , y una manzana con $100 \%$ de habitantes E obtiene un índice de 0 . En la figura 1 (derecha), los colores oscuros están cercanos a un CSM de 0, y los colores claros a un CMs de 100. De todos modos, cabe señalar que el presente índice tiene solo la intención de entregar una visualización a priori de la distribución de grupos, pero no pretende reemplazar el significado que cada grupo atribuye al estatus socioeconómico de sí mismos y de los "otros".

\section{Tabla 1. Resumen del cambio sociodemográfico, 2002-2013}

El censo 2012 tuvo varios problemas en la obtención y tratamiento de los datos (ej. alto nivel de imputación), y finalmente se recomendó repetirlo en 2017. Por tanto, los datos de dicho censo perdieron credibilidad y el acceso a la información quedó deshabilitado.

Dadas estas limitantes, se elaboró una estimación de la población del área de estudio para el ańo 2013 de la siguiente manera. Primero, solo se midió el cambio socioeconómico y demográfico del área a partir de nuevas manzanas y nuevos conjuntos habitacionales construidos. Se asumió, entonces, que el número de predios es igual al número de hogares, y que en las manzanas que se mantienen de 2002 a 2013, la distribución de grupos socioeconómicos y la población es la misma que en 2002. Segundo, se trabajó sobre la base de la cartografía y censo 2002, detallando grupos socioeconómicos por manzana: ABC1, C2, C3, D y E (metodología de marketing) ${ }^{3}$. Tercero, se elaboró un plano actualizado según Plan Regulador de La Florida, Google Earth y observaciones en terreno. Cuarto, se contó el número de predios por manzana, según plano actualizado, obteniendo así el número actual de hogares (tras las nuevas construcciones después de 2002). Quinto, se utilizó un tamaño promedio de hogar según grupo socioeconómico (por deciles de ingreso, según Instituto Nacional de Estadísticas, INE). Sexto, según observaciones en terreno, se imputó la distribución porcentual de grupos socioeconómicos para las manzanas nuevas, desde otras manzanas similares. Y séptimo, para obtener la

3 Si bien esta metodología ha sido bastante cuestionada, esta base de datos era de las únicas disponibles para hacer una primera aproximación a la estratificación social del área. Cabe señalar nuevamente que este estudio utilizó esta base de datos como una referencia inicial, pero el principal factor tomado en cuenta fue la consideración de cada grupo social acerca de qué factores definen ser de clase baja o ser de clase media o media-alta. 
población total por manzana, se dividió el número total de hogares por la sumatoria de los cocientes entre el porcentaje de población por grupo socioeconómico y el tamaño de hogar por grupo.

Para las proyecciones de las figuras 3, 4 y 5 se utilizó el censo 2002 como base, y con el número de viviendas del pre-censo 2011 y las encuestas CASEN (véase sección 5, abajo) de los años 2000 y 2009, se extrapolaron los datos del censo 2002.

\section{Procedimientos de selección de entrevistados, levantamiento de datos y análisis de datos}

Selección de entrevistados. Para reducir la posibilidad de sesgo de selección, antes de reclutar residentes para las entrevistas, se crearon distintos perfiles (basado en edad, ingreso y tamańo familiar), de modo de representar la variedad de los grupos de alto y bajo estatus. Luego, se accedió a los residentes por medio de organizaciones locales (juntas de vecinos, juntas de adelanto), a las que se les pidió contactos de residentes que calzaron con los perfiles antes señalados. Después de conseguir tres residentes en cada grupo social, se siguió con la técnica de "bola de nieve" (o muestreo en cadena), pidiéndole a los entrevistados más contactos entre sus redes sociales. Así, la elaboración de distintos perfiles en cada grupo fue crucial para reducir los sesgos, dado que el éxito de la técnica de "bola de nieve" depende fuertemente de los contactos iniciales.

Levantamiento de datos. Incluyó recolección de literatura sobre la historia del caso, recolección de información espacial y socioeconómica y, lo más importante, un estudio de caso cualitativo para el cual se emplearon entrevistas, observaciones de campo e inventarios espaciales. Las entrevistas en profundidad (semiestructuradas) se dirigieron a residentes de bajo estatus $(\mathrm{N}=20)$, de alto estatus $(\mathrm{N}=20)$ y a actores institucionales $(\mathrm{N}=10)^{4}$, con los que se discutieron experiencias sobre la diversidad socioeconómica, oportunidades para habitantes de bajos ingresos, influencia de las instituciones locales, relaciones entre grupos y el rol de los espacios públicos. Las observaciones de campo se usaron para estudiar espacios clave de encuentro intergrupos 5 , examinándose cómo las jerarquías sociales son desplegadas en situaciones de la vida real. Se desarrollaron veinte observaciones (de tres horas cada una), en las que se combinaron observación pasiva con algunas preguntas a los actores del lugar, guardándose notas y comentarios analíticos. Y los inventarios espaciales sirvieron para estudiar cómo el espacio es usado y transformado, para lo cual se observaron los rastros espaciales de la presencia simbólica de cada grupo social a través de

4 Las instituciones elegidas fueron las siguientes: Escuela Lo Cañas (Municipal), Colegio Quinto Centenario (Particular Subvencionado), Tenencia de Carabineros Los Jardines (La Florida), Departamento de Participación Ciudadana (Municipalidad de La Florida), Departamento de Vivienda (Municipalidad de La Florida), Servicio de Vivienda y Urbanización (serviu, encargado proyecto Las Tinajas), Carlos Montes (diputado por La Florida), Iglesia San José de las Mercedes, Unión Comunal de Allegados, y Agrupación "Red de Defensa de la Precordillera".

5 Se observaron distintos espacios comerciales, distintas plazas, paraderos de buses, y una manifestación ciudadana a nivel comunal. 
mapeos, anotaciones y fotografías. Se desarrollaron diez inventarios (caminatas de dos horas) para mapear y fotografiar usos de suelo no residenciales, usos temporales, signos de actividad, marcadores de estatus, tipos de vivienda, tipos de rejas, etcétera.

Análisis de datos. Este consideró cuatro pasos. Primero, se creó un perfil de barrio con base en la información espacial y cuantitativa recolectada anteriormente (incluyendo estadísticas descriptivas para algunos temas clave). Segundo, se desarrolló una primera vuelta de codificación cualitativa (de entrevistas y notas de campo), durante el trabajo de campo. Se utilizaron códigos descriptivos, separándose a los actores por categorías. La codificación fue abierta, pero también dirigida a explorar las principales variables del estudio (dimensiones de la integración socioespacial). Tercero, se desarrolló una segunda vuelta de codificación, en la que se redujo el exceso de códigos a un número más manejable, creando salidas de cada código y luego resumiendo las ideas en cada cita, de modo de no perder riqueza en la información. Además, en esta etapa se crearon visualizaciones espaciales a partir de los inventarios. Y cuarto, se efectuó una serie de "manipulaciones analíticas", poniendo la información en distintas organizaciones, haciendo matrices de categorías con evidencia específica y creando visualizaciones de datos (ej. diagramas de flujo) para examinar la información y empezar a desarrollar una reconstrucción teórica.

\section{Motivos de la selección del caso y sus características}

El área alrededor de La Loma en La Florida se seleccionó por su representatividad como caso extremo de diversidad socioeconómica en el Gran Santiago. Para medir la diversidad socioeconómica, se creó el Índice de Diversidad Barrial (IDB):

$$
I D B=\frac{\left|P_{a b c 1}-P_{d e}\right|+\left(\left|50-P_{a b c 1}\right|+\left|50-P_{d e}\right|\right)}{2}
$$

Donde:

Pabc1: \% población $\mathrm{ABC} 1$

Pde: \% población DE

El Índice de Diversidad Barrial mide "diversidad” como la situación más cercana a estar 50\%-50\% entre los dos grupos más opuestos (en poder y estatus) en una ciudad. El índice va de 0,0 a 1,0, donde 0,0 representa la más alta diversidad de un barrio (o más baja segregación), y 1,0 la más baja diversidad (o más alta segregación), ya sea de residentes pobres o ricos. Esta situación de 50\%-50\% representaría una distribución de poder relativamente más igualitaria entre grupos extremos y, por lo mismo, no está en proporción con la población total de un grupo social en la ciudad (como lo es con el Índice de Disimilaridad). Usando el IDB, entonces, la figura 7 abajo muestra la localización del área de estudio en un mapa de diversidad a partir de zonas censales en el Gran Santiago (colores oscuros indican IDB cercano a $0, y$ colores claros indican IDB cercano a 1 ). 
Figura 7 Localización del área de estudio en mapa de diversidad barrial (IDB)



FUENTE ELABORACIÓN PROPIA A PARTIR DEL CENSO 2002

Tal como se ha repetido en este anexo, la selección del caso mediante el IDB es solo una aproximación inicial, pero no reemplaza el significado de la diversidad socioeconómica del barrio para sus habitantes y actores institucionales (como la descripción de "diversidad abismante", por parte de una funcionaria del Municipio).

\section{Siglas y fuentes}

CASEN: la encuesta de Caracterización Económica Nacional (CASEN) es realizada por el Ministerio de Desarrollo Social de Chile cada dos ańos y su objeto de estudio son los hogares. Los datos de la encuesta son públicos y se pueden obtener en: http:// www.redatam.org/redchl/mds/casen/

SIMCE: la prueba SIMCE, del sistema nacional de evaluación de resultados de aprendizaje de Chile, entrega información sobre los estándares de aprendizaje de estudiantes de diferentes niveles de enseñanza. Los resultados son públicos y se pueden obtener en: http://www.agenciaeducacion.cl/simce/bases-de-datos-nacionales/

\section{Definición de cuadrantes 169 y 273}

Los cuadrantes son divisiones de territorio de una determinada unidad policial, definidos por el Plan Cuadrante de Seguridad Preventiva (o Plan de Vigilancia por Cuadrantes). Carabineros de Chile, la policía uniformada de Chile, recopila información acerca de los delitos ocurridos en cada cuadrante. La información es pública 
y se solicita a Carabineros de Chile mediante el sistema de transparencia: http:// www.carabineros.cl/transparencia/solicitud_informacion.html

El cuadrante 169 limita con Santa Julia al norte, límite urbano de La Florida al oriente, Trinidad Oriente al sur, y avenida La Florida al poniente. El cuadrante 273 limita con Walker Martínez al norte, Tobalaba al oriente, Santa Julia al sur, y avenida La Florida al poniente. Si bien los mencionados cuadrantes abarcan un área más grande que el área de estudio, los datos comparados de los últimos años entregan un panorama general de los niveles de delincuencia de la zona.

\section{Referencias bibliográficas}

Alvarado, M. \& Fernández, H. (2011). Una narración fundacional para una antropología filosófica chilena: Raza chilena de Nicolás Palacios. Cinta de Moebio, 40(1), 47-63. En http://www.facso.uchile.cl/publicaciones/moebio/40/alvarado.html

Arthurson, K. (2012). Social mix and the city: Challenging the mixed communities consensus in housing and urban planning policies. Collingwood, Australia: Csiro Publishing.

Barozet, E. (2011). Zu den Herausforderungen der Ungleichheitsmessung in Lateinamerika. Einige kritische Anmerkungen zu den existierenden Instrumenten und Verbesserungsvorschläge anhand des chilenischen Fallbeispiels. En H. J. Burckhardt \& I. Wehr (Eds.), Latin America's denied social contract: On the diffculties of transforming political into social participation (pp. 309-330). Baden-Baden: Nomos. En http:// www.desigualdades.cl/wp-content/uploads/2010/11/Barozet-capitulo-Nomosalem $\% \mathrm{C} 3 \% \mathrm{~A} 1 \mathrm{n} 2 . \mathrm{pdf}$

Bourdieu, P. (1999). La miseria del mundo. Buenos Aires: Fondo de Cultura Económica.

Cashin, S. (2004). The failures of integration: How race and class are undermining the American dream. Nueva York: Public Affairs.

Chamboredon, J.-C. \& Lemaire, M. (1970). Proximité spatiale et distance sociale. Les grands ensembles et leur peuplement. Revue Française de Sociologie, 11(1), 3-33. doi: $10.2307 / 3320131$

Contardo, Ó. (2012). Siútico: Arribismo, abajismo y vida social en Chile. Santiago: B-Vergara.

Contreras, D., Cooper, R., Herman, J. \& Neilson, C. (2005). Movilidad y vulnerabilidad en Chile. Expansiva En foco, 56(1), 1-16. En http://expansiva.cl/media/en_foco/ documentos/12102005130329.pdf

De la Jara, A. M. (2003). La Florida, construyendo futuro. Santiago: ONG Cordillera.

DeFilippis, J. \& Fraser, J. (2010). Why do we want mixed-income housing and neighborhoods? En J. Davies \& D. Imbroscio (Eds.), Critical urban studies: New directions (pp. 135147). Albany, NY: State University of New York Press.

Ducci, M. E. (2000). Santiago: Territorios, anhelos y temores. Efectos sociales y espaciales de la expansión urbana. EURE, 26(79), 5-24. http://dx.doi.org/10.4067/S025071612000007900001

Durkheim, E. (1997). The division of labor in society. Nueva York: Free Press. 
Espinoza, V. \& Barozet, E. (2009). ¿De qué hablamos cuando decimos "clase media"? Perspectivas sobre el caso chileno. Serie En Foco, 142(1), 1-33. En http://www. expansiva.cl/publicaciones/en_foco/detalle.tpl?iddocumento=27082009115400

Galster, G. \& Killen, S. (1995). The geography of metropolitan opportunity: A reconnaissance and conceptual framework. Housing Policy Debate, 6(1), 7-43. doi: $10.1080 / 10511482.1995 .9521180$

Gans, H. (2008). Involuntary segregation and the ghetto: Disconnecting process and place. City \& Community, 7(4), 353-357.

Hidalgo, R. (2004). De los pequeños condominios a la ciudad vallada: Las urbanizaciones cerradas y la nueva geografía social en Santiago de Chile (1990-2000). EURE, 30(91), 29-52. http://dx.doi.org/10.4067/S0250-71612004009100003

Jargowsky, P. (1997). Poverty and place: Ghettos, barrios, and the American city. Nueva York: Russell Sage Foundation.

Marcuse, P. (2005). Enclaves yes, ghettos no. En D. Varady (Ed.), Desegregating the city: Ghettos, enclaves, and inequality (pp. 15-30). Albany, NY: State University of New York Press.

Márquez, F. \& Pérez, F. (2008). Spatial frontiers and neo-communitarian identities in the city: The case of Santiago de Chile. Urban Studies, 45(7), 1461-1483. doi: $10.1177 / 0042098008090684$

Massey, D. \& Denton, N. (1993). American apartheid: Segregation and the making of the underclass. Cambridge, ma: Harvard University Press.

Ostendorf, W., Musterd, S. \& De Vos, S. (2001). Social mix and the neighbourhood effect: Policy ambitions and empirical evidence. Housing Studies, 16(3), 371-380. doi: 10.1080/02673030120049724

Pérez, F. (2006). Prácticas y representaciones de la vida barrial: El caso de los condominios y los conjuntos de vivienda social. Proposiciones, 35(1), 84-98. En http://www.sitiosur. $\mathrm{cl} / \mathrm{r} \cdot \mathrm{php}$ ?id=822

Pérez, M. (2011). The emergence of gated communities in the poor periphery: Reflections on the new urban segregation and social integration in Santiago, Chile. Berkeley Planning Journal, 24(1), 1-13. En http://escholarship.org/uc/item/31b359g4

Préteceille, E. (2003). A evolução da segregaçấo social e das desigualdades urbanas: O caso da metrópole parisiense nas últimas décadas. Caderno CRH, 16(38), 27-48. En http:// www.cadernocrh.ufba.br/viewarticle.php?id=142

Raczynski, D. (1994). Políticas sociales y programas de combate a la pobreza en Chile: Balance y desafíos. Colección Estudios cieplan, 39(1), 9-73. En http://www.cieplan.org/ biblioteca/detalle.tpl?id=65

Rodríguez, A. \& Winchester, L. (2001). Santiago de Chile: Metropolización, globalización, desigualdad. EURE, 27(80), 121-139. http://dx.doi.org/10.4067/S025071612001008000006

Roitman, S. (2011). Distinción social y hábitat residencial en América Latina. Revista INVI, 26(73), 17-71. http://dx.doi.org/10.4067/S0718-83582011000300002

Ruiz-Tagle, J. (2013). A theory of socio-spatial integration: Problems, policies and concepts from a us perspective. International Journal of Urban and Regional Research, 37(2), 388-408. doi: 10.1111/j.1468-2427.2012.01180.x 
Ruiz-Tagle, J. \& López, E. (2014). El estudio de la segregación residencial en Santiago de Chile: Revisión crítica de algunos problemas metodológicos y conceptuales. EURE, 40(119), 25-48. http://dx.doi.org/10.4067/S0250-71612014000100002

Sabatini, F. (1999). Crítica a la cultura antiurbana. Ambiente y Desarrollo, 15(1), 25-37. En http://cipma.cl/web/200.75.6.169/RAD/1999/1-2_Sabatini.pdf

Sabatini, F., Cáceres, G. \& Cerda, J. (2001). Segregación residencial en las principales ciudades chilenas: Tendencias de las tres últimas décadas y posibles cursos de acción. EURE, 27(82), 21-42. http://dx.doi.org/10.4067/S0250-71612001008200002

Sabatini, F., Rasse, A., Mora, P. \& Brain, I. (2012). ¿Es posible la integración residencial en las ciudades chilenas?: Disposición de los grupos medios y altos a la integración con grupos de extracción popular. EURE, 38(115), 159-194. http://dx.doi.org/10.4067/ S0250-71612012000300008

Sabatini, F. \& Salcedo, R. (2007). Gated communities and the poor in Santiago, Chile: Functional and symbolic integration in a context of aggressive capitalist colonization of lower-class areas. Housing Policy Debate, 18(3), 577-606. doi: 10.1080/10511482.2007.9521612

Salcedo, R. \& Torres, A. (2004). Gated communities in Santiago: Wall or frontier? International journal of urban and regional research, 28(1), 27-44. doi: 10.1111/j.03091317.2004.00501.x

Sampson, R., Morenoff, J. \& Gannon-Rowley, T. (2002). Assessing "neighborhood effects": Social processes and new directions in research. Annual Review of Sociology, 28(1), 443-478. doi: 10.1146/annurev.soc.28.110601.141114

Saravi, G. (2008). Mundos aislados: Segregación urbana y desigualdad en la Ciudad de México. EURE, 34(103), 5-25. http://dx.doi.org/10.4067/S0250-71612008000300005

Savage, M. (2010). The politics of elective belonging. Housing, Theory and Society, 27(2), 115135. doi: $10.1080 / 14036090903434975$

Strobl, R. (2007). Social integration and inclusion. En G. Ritzer (Ed.), The Blackwell Encyclopedia of Sociology (pp. 4437-4440). Malden, MA: Blackwell.

Torche, F. (2006). Una clasificación de clases para la sociedad chilena. Revista de Sociología, 20(1), 15-43. En http://www.revistadesociologia.uchile.cl/index.php/RDS/article/ viewFile/27529/29197

Wacquant, L. (2009). The body, the ghetto and the penal state. Qualitative Sociology, 32(1), 101-129. doi: 10.1007/s11133-008-9112-2

Waldman, G. (2004). Chile: Indígenas y mestizos negados. Política y Cultura, 21(1), 97-110. En http://www.redalyc.org/articulo.oa?id=26702107

Wilson, W. J. (1987). The truly disadvantaged: The inner city, the underclass, and public policy. Chicago, IL: University of Chicago Press.

Wirth, L. (1927). The ghetto. American Journal of Sociology, 33(1), 57-71. En http://bit. ly/1Vvhq11 
